\title{
Improved hybrid algorithm based on GA and local search method for asymmetrical 9-level inverter
}

\author{
Rim Feyrouz Abdelgoui ${ }^{1}$, Rachid Taleb ${ }^{2}$, Abderrahim Bentaallah $^{3}$, Fayçal Chabni ${ }^{4}$ \\ ${ }^{1,3}$ Electrical Engineering Department, Djillali Liabes University, Sidi Bel Abbes, Algeria \\ Intelligent Control and Electrical Power Systems Laboratory (ICEPS) \\ ${ }^{2,4}$ Electrical Engineering Department, Hassiba Benbouali University, Chlef, Algeria \\ Laboratoire Génie Electrique et Energies Renouvelables (LGEER)
}

\begin{tabular}{|c|c|}
\hline Article Info & ABSTRACT \\
\hline Article history: & \multirow{6}{*}{$\begin{array}{l}\text { Selective harmonic elimination has emerged as an in-depth research method } \\
\text { to replace traditional PWM technology. This study demonstrates the selective } \\
\text { harmonic elimination by using a hybrid Genetic algorithm GA and local } \\
\text { search (GA-LS) method of a uniform asymmetric multilevel inverter called } \\
\text { USAMI That removes the higher-order harmonics defined while maintaining } \\
\text { the fundamental voltage needed. This new technology can be implemented at } \\
\text { any USAMI level. For example, in this article, we plan to use USAMI at } 9 \\
\text { levels and find the optimal switching angle to remove the } 5^{\text {th }}, 7^{\text {th }} \text {, and } 11^{\text {th }} \\
\text { harmonics. }\end{array}$} \\
\hline Received Aug 14, 2020 & \\
\hline Revised Sep 7, 2020 & \\
\hline Accepted Sep 27, 2020 & \\
\hline Keywords: & \\
\hline & \\
\hline
\end{tabular}

Multilevel inverter

SHE

THD

USAM

This is an open access article under the CC BY-SA license.

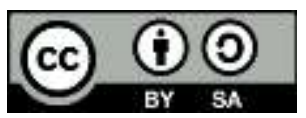

\section{Corresponding Author:}

Rim Feyrouz Abdelgoui

Electrical Engineering Department

Djillali Liabes University, Sidi Bel Abbes, Algeria

Intelligent Control and Electrical Power Systems Laboratory (ICEPS)

Email: rf.abdelgoui@gmail.com

\section{INTRODUCTION}

The main application of the multilevel inverter topology is generally electric traction and drive locomotives of $3 \mathrm{KV}$, electric boat variable speed drives, and transmission systems. The use of multilevel converters in industrial equipment is inspired by energy benefits and has now been widely demonstrated: energy is significantly reduced. the current harmonic distortion rate is also decreased and the power factor is improved. Cascaded H-bridge multi-level inverters CHB utilize H-bridge cells linked in series with separate DC voltage source attached to each of the H-bridge cells. There are two available kinds of CHB multi-level inverters from the point of view of the value of the DC voltage sources: symmetrical and asymmetrical topology.

Several topologies have been tested and presented with multilevel inverters which contain neutralpoint-clamped inverters [1,2], imbricated cells, also flying capacitor inverters [2,3], and linked cell sequence inverters, also referred to as cascaded inverters [4]. Nevertheless, due to the nature of higher number levels, the are some benefits to the topology that utilizes series-attached cell inverters, such as the lower level of voltage $(d U / d t)$ generating fewer mutual-mode voltage through machine windings $[2,5]$. Also, this structure is easy and allows it quickly extendable with his modular model for every number of the required output voltage. Figure 1(b) shows a basic model of this configuration including $k$ partial cells described by Figure 
1(a). A $d c$-voltage source supplied the $j^{\text {th }}$ single-phase inverter $U_{d j}(j=1 \ldots k)$. The relation among $k$ representing the number of inverters connected in series per phase and $N$ describing the total of output voltage levels provided through this configuration is defined by $N=2 k+1$, if each partial inverter has similar voltages [2].

In many of the known structures of multilevel converters [6], the total of power equipment requested relies upon the output voltage level required [7]. Nevertheless, the rise in the converter circuit is a result of the number of increased power semiconductors, control complexity, and costs. A uniform step asymmetrical multilevel inverters could be employed to provide an enormous number of output levels with no rise in the size of converters [8-10]. Making sure that the Total Harmonic Distortion is within reasonable limits of the output voltage waveform is the main question in constructing an efficient multilevel inverter. In order to maintain a small THD [11], selective harmonic elimination has been rigorously analyzed. A series of nonlinear transcendental equations are generated by the output voltage waveform computation utilizing Fourier theory.

if exists an answer to these equations, it offers the necessary switching angles for some fundamental element and the chosen harmonic profile. Iterative approaches have been used to resolve these collections of equations, such as the Newton-Raphson method [12]. This approach relies on derivatives and can lead to local optimum, also only a careful selection of the initial parameters assures convergence [13]. Other method is provided in [14], which is based on transforming the transcendental equation to polynomial equations, where the resulting method is applied to calculate the angles of switching to remove different harmonics. However, this method seems unimportant because the level of the polynomial of the mathematical design increase when the total of inverter levels rises. This is likely to result in numerical complexity and also a major computational burden.

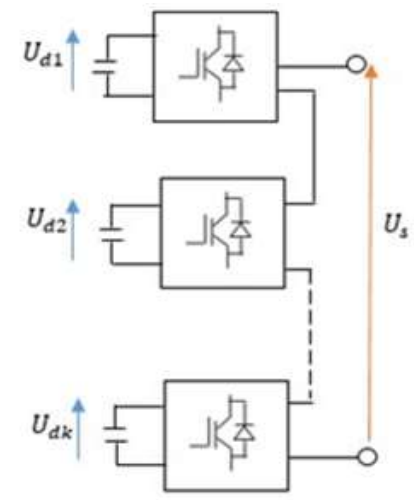

(a)

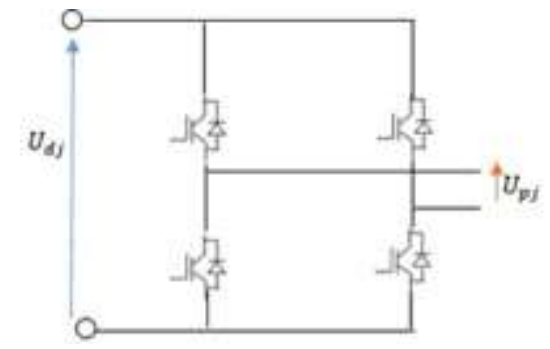

(b)

Figure 1. (a) A series-connected topology of multilevel inverters with k partial cells,

(b) Partial structure of cells

Genetic Algorithm abbreviated by GA is a very effective algorithm that might resolve nearly all optimization issues, imitates the natural evolution mechanism, and is mostly used to attain the optimal solutions $[10,14]$. In order to obtain the perfect local search in GA, the hybrid algorithm (GA-LS) was created. It is a mixture of GA $[15,16]$ and Local Search. To evaluate the optimal switching angles, this combination was implemented for the 9-level USAMI.

\section{DESIGN OF USAMI}

As possible, multilevel inverters generate many identical voltages levels to the reference signal at the ac terminal. $U_{s l}, U_{s 2}, \ldots U_{s N}$ represent $N$ voltage levels which composed a conventional sine exit voltage waveform. The step of the output voltage is characterized through the difference among two successive voltages, if this step $\Delta U$ among all voltage levels is identical, this inverter is called «Uniform Step multilevel inverter » [17]. This constant step is equivalent to the lowest dc-voltage, $U_{d l}$ [2], in this situation. It is possible to describe this by:

$$
\left|U_{s l}-U_{s(l-1)}\right|=\Delta U=U_{d 1}, l=2 K N
$$


The converter is known as the non-uniform phase AMI or varying AMI if this isn't the situation. To feed the partial cells (inverters) which compose his topology via dc voltage sources under the following requirements:

$$
\left\{\begin{array}{c}
U_{d 1} \leq U_{d 2} \leq U_{d 3} \leq \cdots \leq U_{d k} \\
U_{d j} \leq 1+2 \sum_{l=1}^{j-1} U_{d l}
\end{array}\right.
$$

Here $k$ is the total of partial cells in each phase. $N$ could be concluded from $j=1 \ldots k$.

$$
N=1+2 \sum_{j=1}^{k} \frac{U_{d j}}{U_{d 1}}
$$

This relation essentially changed the total of levels that the multilevel geometry produces. In fact, the $N$ value relies on the cell count per phase plus the dc voltages provided [2].

In (3) approve a variety of anserws. For example,for the three partalials inverters to achieve a output of 13 levels, there can be two potential combinations of voltages levels $U_{d 1} \in\{1,1\}, U_{d 2} \in\{1,2\}$ and $U_{d 3} \in$ $\{4,3\}$ but to generate a 15 -level global output, there are three possible combinations $U_{d 1} \in\{1,1,1\}, U_{d 2} \in\{1$, $2,3\}$ and $U_{d 3} \in\{5,4,3\}$. Figure 3 exhibit the alternative output voltages of the 9-level inverter's three partial cells indicated $U_{p 1}, U_{p 2}$ and $U_{p 3}$ with $k=3$. Dc-voltages of cells are given by $U_{d 1}=1 p . u$., $U_{d 2}=1 p . u$. and $U_{d 3}$ $=2 p . u$.It isbetter to use the following combinations: $U_{p 1} \in\{-1,0,1\}, U_{p 2} \in\{-1,0,1\}$ and $U_{p 3} \in\{-2,0,2\}$. The outcomes is a produced 9-level output voltage : $U_{s} \in\{-4,-3,-2,-1,0,1,2,3,4\}$.

Various commutation sequences can produce output voltage levels. There are four alternative commutation sequences, for example $U_{p 1} \in\{-1,0,1,1\}, U_{p 2} \in\{1,0,-1,1\}$ and $U_{p 3} \in\{2,2,2,0\}$ leading in $U_{s}=2 p . u$.To optimize the switching process of the inverter [2], these redundant combinations can be picked. Such distinct possibilities provided by the partial inverter output voltage and the redundancies among them in delivering the identical output voltage level could be treated as permutations that can be used to doing optimization of the use of USAMI. Multi-level inverter's standard output voltage waveform as shown in Figure 2.

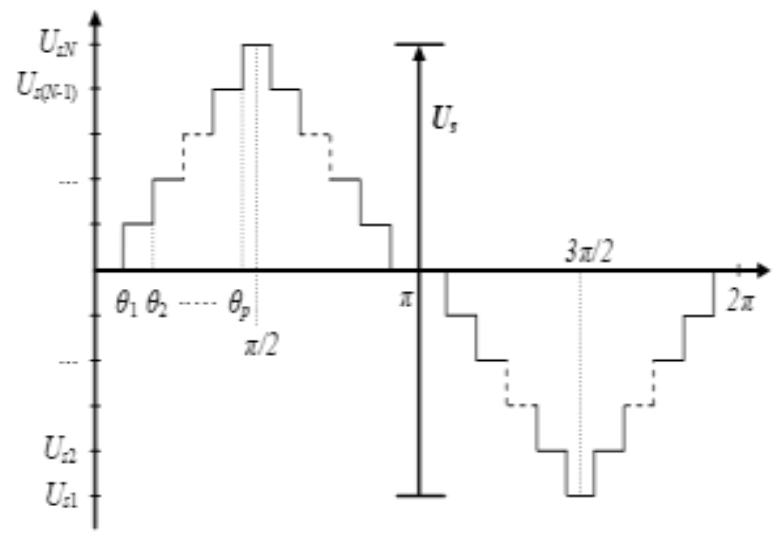

Figure 2. Multi-level inverter's standard output voltage waveform

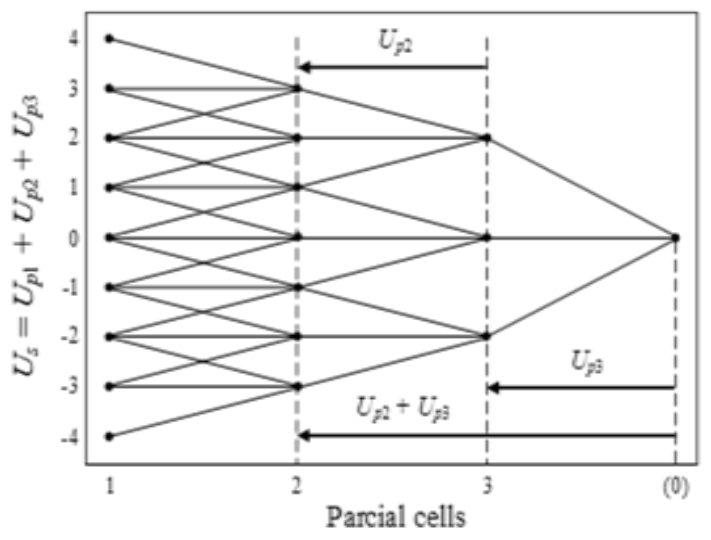

Figure 3. Each partial inverter 's possible output voltages to generate $N=9$ levels with $k=3$ cells per phase $\left(U_{d 1}=1\right.$ p.u., $U_{d 2}=1$ p.u. and $U_{d 3}=$ 2p.u.)

\section{MODULATION CONTROL}

In general, both the conventional theory of PWM control and the SVPWM (space vector PWM) approach applied to the control of symmetrical multilevel inverter modulation $[18,19]$, which can be used to control USAMI. Due to the high switching frequencies of these methods, it causes extra losses. Thus, the low-switching frequency command techniques, for instance, selective harmonic elimination, show important solutions [20-22].

The SHE is focused on the voltage $U_{s}$ produced by the Fourier analysis of output of the uniform step asymmetrical multilevel inverter as shown in Figure 2. $U_{s}$ is symmetric in half and a quarter of a period. As a 
consequence, all the harmonic elements are null. Therefore, for the $U_{s}$ voltage, the Fourier series expansion is [23]:

$$
U_{s}=\sum_{n=1}^{\infty} U_{n} \sin (n \omega t), \text { with } U_{n}=\frac{4 U_{d 1}}{n \pi} \sum_{i=1}^{p} \cos \left(n \theta_{i}\right)
$$

Where: $U_{n}$ defines largeness of the harmonic term of rank $n, p$ represents is the total of switching angles per quarter waveform given by $p=(N-1) / 2$ and $\theta_{i}$ describes the $i^{\text {th }}$ switching angle [2,22].

The number of switching angles shown in (4) is determined by maintaining the amplitude of the fundamental term and rescinding the $p-1$ element. Virtually, $\theta_{1}, \theta_{2}, \theta_{3}$ and $\theta_{4}$ are necessary for deleting harmonics with non-multiple of 3 , therefore 5, 7 and 11 and odd rank). In the situation of the USAMI 3-Phase 9-level formed of $k=3$ partial inverters provided with $U_{d l}, U_{d 2}$ and $U_{d 3}$ which $U_{d l}=1$ p.u., $U_{d 2}=1$ p.u and $U_{d 3}=2 p . u$.we can find the switching angles by resolving the correspondent below this [2, 22, 23]:

$$
\left\{\begin{array}{c}
\sum_{i=1}^{p=4} \cos \left(\theta_{i}\right)=\pi r \\
\sum_{i=1}^{p=4} \cos \left(n \theta_{i}\right)=0 \text { for } n \in\{5,7,11\}
\end{array}\right.
$$

Which $r$ represents the modulation rate given by $r=U_{l} / 4 U_{d l}$ is the. The answer of (5) should as well meet the requirement of:

$$
0<\theta_{1}<\theta_{2}<\theta_{3}<\theta_{4}<\pi / 2
$$

For the method of optimization, which is chosen to measure the efficacity of removing the chosen harmonics rank through holding the fundamental element at a predefined value, an objective function is then required. Consequently, This objective function is represented as [22, 3]:

$$
F(\theta)=F\left(\theta_{1} \Lambda \theta_{4}\right)=\left(\sum_{i=1}^{p=4} \cos \left(\theta_{i}\right)-\pi r\right)^{2}+\sum_{i=5,7,11} U_{i}^{2}
$$

By optimizing (7) according to the constraint (6) and, as a result, It achieves the necessary harmonic profile. The non-linearity of (5) is the key difficulty because many iterative methods are confronted with difficulties of convergence and other approaches are complicated like elimination utilizing resulting [10] and Walsh function [24]. Therefore, hybrid GA with local search methods (GA-LS) is a simple approach and worth considering.

\section{PROPOSED HYBRID ALGORITHM (GA-LS)}

To solve the problem of local search in GA, A hybrid algorithm for genetic optimization has been established. The hybrid GA is a combination of local search (LS) and the Algorithm of Genetic Optimization $[2,15,24]$. In this research, using hybrid genetic algorithms with local search methods (GA-LS), the MATLAB toolbox was used to decide the optimal switching angles. By using a composite function that operates after the end of the GA, the value of the given objective function is reduced. The final point defined by the GA is utilized as an initial point for the hybrid function. Fmincon, which is a local search tool, is favored in this study as a hybrid function, and it is often utilized to calculate the minimum value of the suggested cost function. The flow chart is proven in Figure 4 for the hybrid algorithm for SHE .

To find the optimal angles $\left(\theta_{1}, \theta_{2}, \theta_{3}, \theta_{4}\right)$, for 9-level USAMI, this process was utilized to remove the $5^{\text {th }}, 7^{\text {th }}$, and $11^{\text {th }}$ harmonics. The outcome is shown in Figure 5 in which one can see the existence of two possible angle solutions for $0.70 \leq r \leq 0.76$. On the other hand, no solution is approved by the system for $r<$ $0.629,0.64<r<0.7$ and $0.897<r<0.921$. With all other $r$ values, the method seems to have the only answer

For two potential angle solutions, it is a straightforward way to choose the one that gives the smallest THD achieved from (8) to have a particular solution $\theta_{i}$. The THD that corresponds to the solutions shown in Figure 5 is displayed in Figure 6 [25].

$$
\mathrm{THD}=\sqrt{\sum_{\mathrm{n}=5,7, . .}^{\infty}\left(\frac{1}{\mathrm{n}} \sum_{\mathrm{i}=1}^{\mathrm{p}=4} \cos \left(\mathrm{n} \theta_{i}\right)\right)^{2}} / \sum_{\mathrm{i}=1}^{\mathrm{p}=4} \cos \left(\theta_{i}\right)
$$




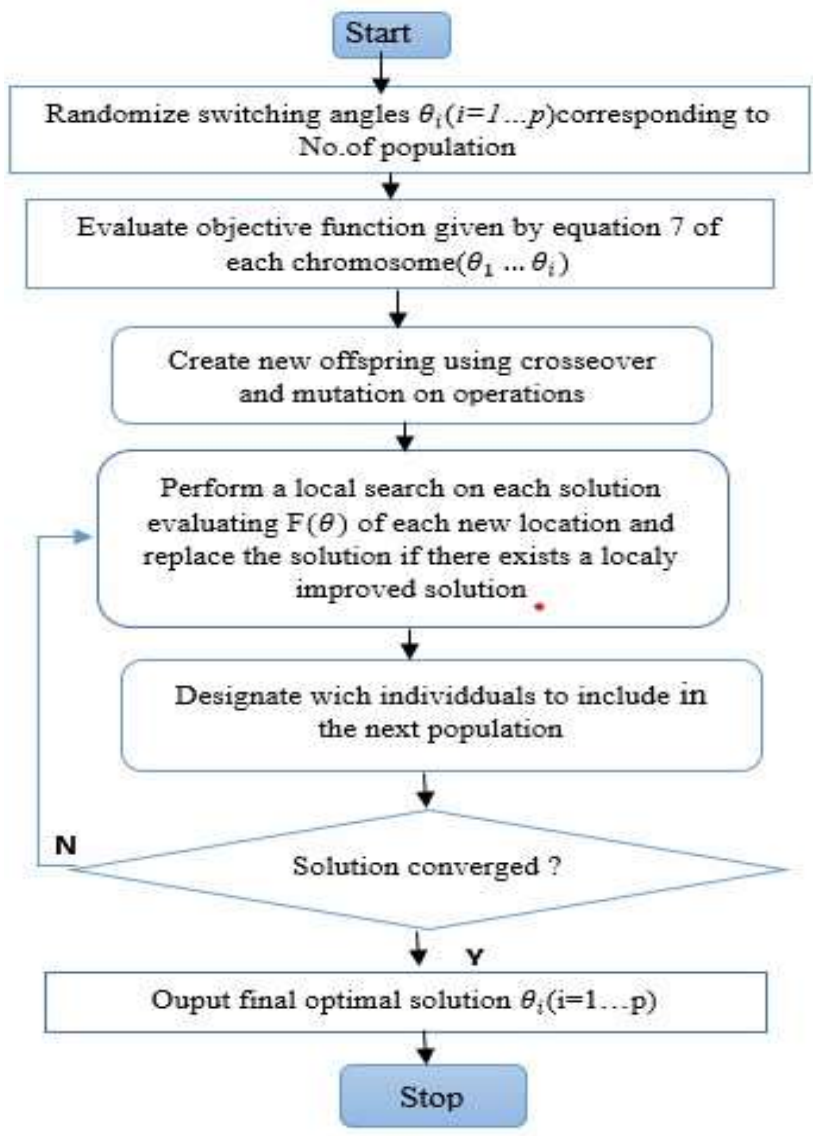

Figure 4. GA-LS's flowchart for SHE

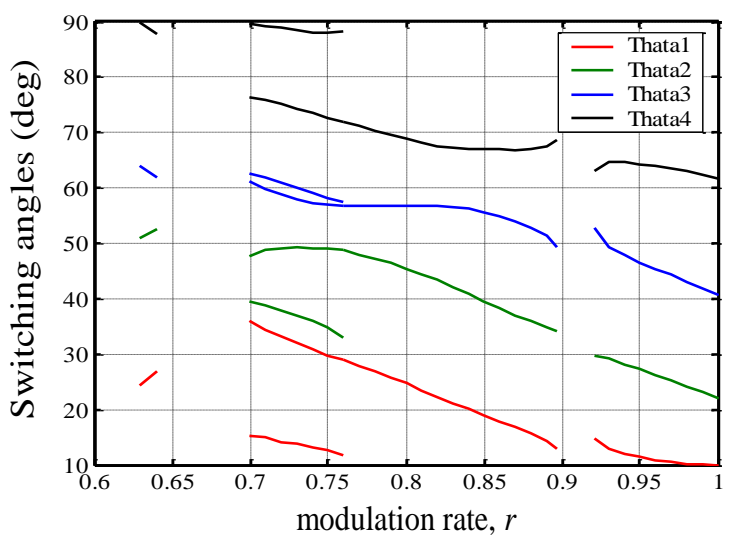

Figure 5. All switching angles versus $r$ for a 9-level USAMI

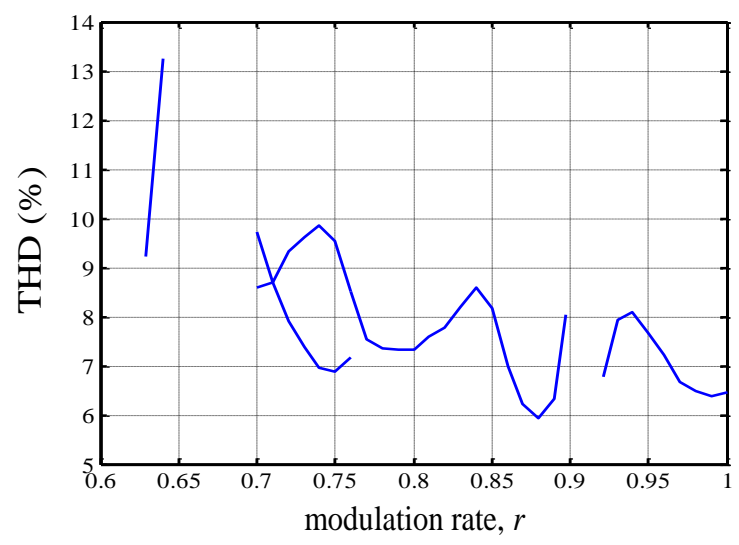

Figure 6. THD versus $r$ for all switching angles

A comparison is provided in Table 1 among the traditional GA and the hybrid algorithm (GA-LS) suggested for the computing time and the identical THD. The developed algorithm, which clearly illustrates the superiority of the technology implemented in terms of computational burden and performance waveform efficiency, is both extremely quick and optimum than traditional GA.

Table 1. Comparison among traditional GA and the GA-LS algorithm proposed

\begin{tabular}{ccc}
\hline Technique & THD \% & Computational time [s] \\
\hline GA & 7.22 & 12.45 \\
GA-LS & 2.17 & 1.13 \\
\hline
\end{tabular}




\section{TEST RESULTS}

Simulations were performed in this section to test the GA-LS method presented in Section 4. utilizing Matlab-Simulink. Uniform Step Asymmetrical Multilevel Inverter 9-level supplied by three voltage sources $U_{d l}=1$ p.u., $U_{d 2}=1$ p.u. and $U_{d 3}=2 p . u$. $\left(U_{d 1}=250 \mathrm{~V}, U_{d 2}=250 \mathrm{~V}\right.$ and $\left.U_{d 3}=500 \mathrm{~V}\right)$. connected to Induction motor that follwing data: $R_{s}=0.228 \Omega$ (Stator resistance), $R_{r}=0.332 \Omega$ (Rotor resistance), $L_{s}$ $=0.0084 \mathrm{H}($ Stator inductance $), L_{r}=0.0082 \mathrm{H}($ Rotor inductance $), L_{m}=0.0078 \mathrm{H}$ (mutual inductance),$P=$ 3 (number of pole pairs), $J=20 \mathrm{~kg} . \mathrm{m} 2$ (Rotor initia), $P_{n}=1 \mathrm{MW}$ (Rated power), $K_{f}=0.008 \mathrm{Nm} . \mathrm{s} . \mathrm{rad}^{-1}$ (viscous friction cofficient).

In this experience, we use $r=0.75$ to generate a fundamental voltage of $U_{l}$ which $U_{1}=4$ $r U_{d l}=3 p$.u(i.e., $\left.U_{I}=750 \mathrm{~V}\right)$ and $f=50 \mathrm{hz}$. As revealed in Figure 5, it can be noted that there are two possible solutions for $r=0.75$ that can reduce THD (i.e.6.98\%) is adopted as shown in Figure 6. Figure 7 displayed the output voltages $U_{p 1}, U_{p 2}$, and $U_{p 3}$ of each partial inverter, and $U_{a}$ the phase a voltage

The harmonic composition of $U_{a}$ is determined by the utilization of the Fast Fourier Transform (FFT) as defined in Figure 8. This figure demonstrates that, as expected, there are no $5^{\text {th }}, 7^{\text {th }}$, and $11^{\text {th }}$ harmonics in the signal. It is not necessary to eliminate the $3^{\text {rd }}, 6^{\text {rdd }}$ and $9^{\text {th }}$, etc in each phase, because the line voltage is automatically annulled. Measure and confirm that the THD line voltage is $6.91 \%$ which is positive compared to the expected value of $6.89 \%$ as illustrated in Figure 6.

Figure 9 indicates the phase "a "of current $i_{a}$ conformable to $U_{a \text {. }}$. Figure 10 gives the harmonic content of the current, we should note that the harmonic tenor of $U_{a}$ is bigger than $i_{a}$. This is the consequence of the filtration provided by the motor inductance. The new THD is $1.08 \%$.
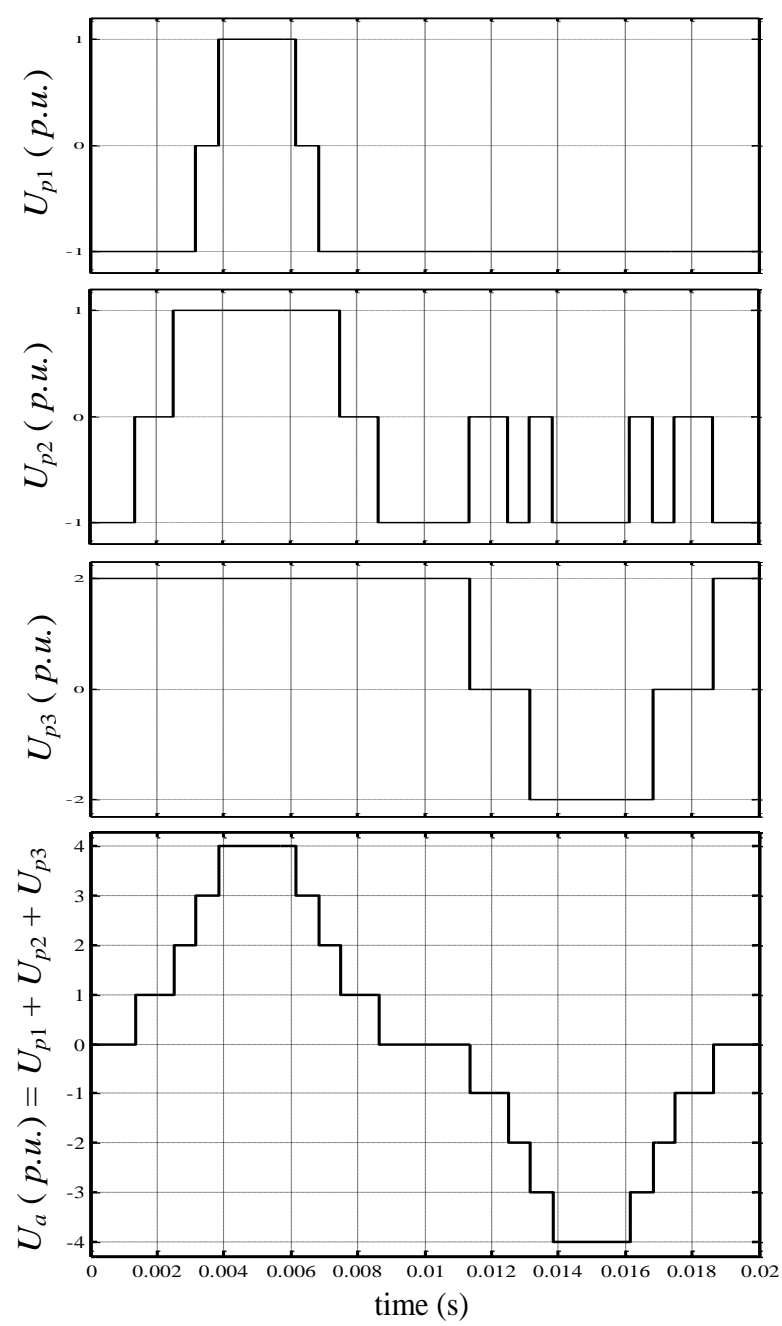

Figure 7. Each partial inverter's output voltages $(\mathrm{r}=0.75)$ 


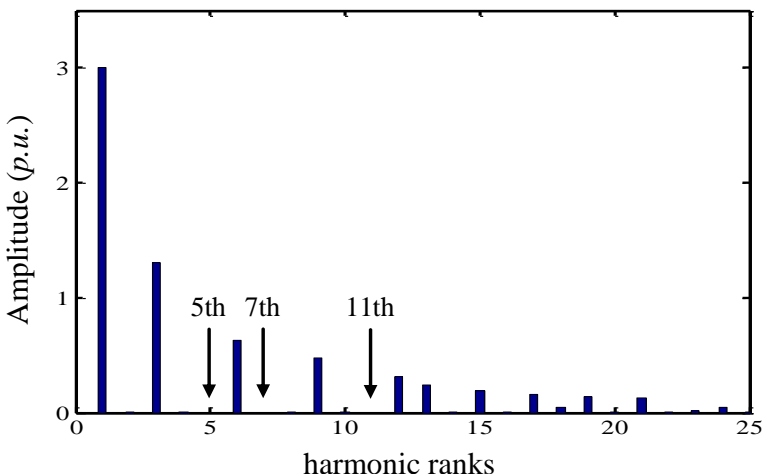

Figure 8. Ua's Harmonic Output

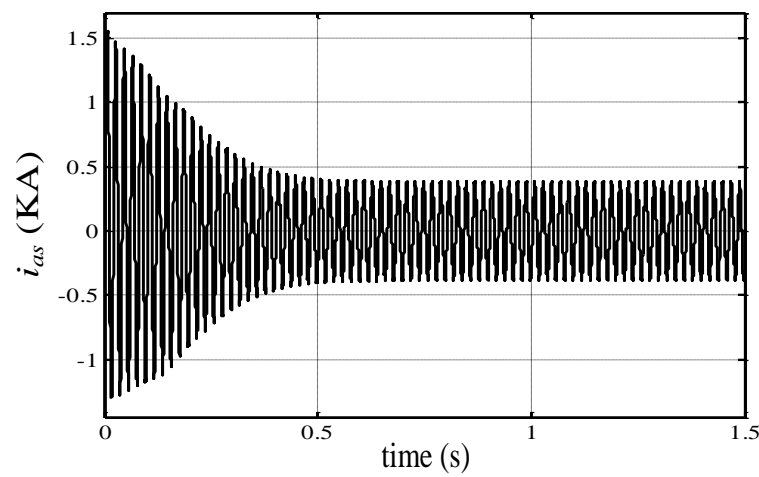

Figure 9. Phase a of current that corresponds to Ua

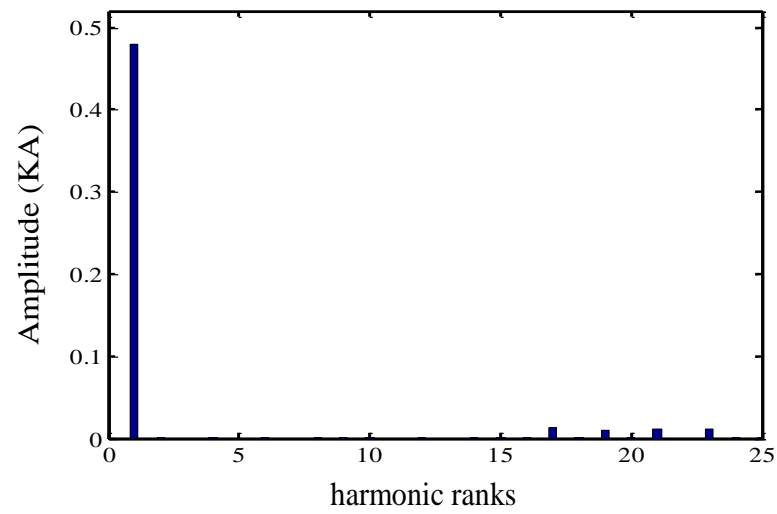

Figure 10. harmonic 's output of the phase a current ia

\section{CONCLUSION}

This paper suggests a hybrid algorithm (GA-LS) for the optimum angle of switching to remove some harmonic order for the 9-levels USAMI. The results show that in the USAMI 9-level harmonics of $5^{\text {th }}$, $7^{\text {th }}$ and $11^{\text {th }}$ order are effectively removed. The proposed technique is comparable to traditional GA In view of computing time and resulting THD, Where it shows that the algorithm might be applied effectively to selective harmonic elimination of USAMI and both the computing-time and THD can be significantly decreased. For any problem, that needs optimization as part of this approach, GA-LS can be used. It may too be included in several applications for power electronics.

\section{REFERENCES}

[1] S. Ponkumar, S. M. Rivera, F. Kamroon and S. G. Kumar, "Realization of cascaded multilevel inverter," 2017 CHILEAN Conference on Electrical, Electronics Engineering, Information and Communication Technologies (CHILECON), Pucon, 2017, pp. 1-7, doi: 10.1109/CHILECON.2017.8229701.

[2] R. Taleb, M. Helaimi, D. Benyoucef, and Z. Boudjema, "Genetic algorithm application in asymmetrical 9-level inverter," International Journal of Power Electronics and Drive Systems. vol. 7, no. 2, pp. 521-530, 2016.

[3] G. A. Saccol, J. C. Giacomini, A. L. Batschauer and C. Rech, "Comprehensive Analysis of Single-Phase FullBridge Asymmetrical Flying Capacitor Inverters," in IEEE Transactions on Industry Applications, vol. 55, no. 2, pp. 1775-1786, March-April 2019, doi: 10.1109/TIA.2018.2883549.

[4] T. D. C. Busarello, A. Mortezaei, H. K. M. Paredes, A. Al-Durra, J. A. Pomilio and M. G. Simões, "Simplified Small-Signal Model for Output Voltage Control of Asymmetric Cascaded H-Bridge Multilevel Inverter," in IEEE Transactions on Power Electronics, vol. 33, no. 4, pp. 3509-3519, April 2018, doi: 10.1109/TPEL.2017.2704919.

[5] Arikesh A., A. K. Parvathy, "Modular multilevel inverter for renewable energy applications", International Journal of Electrical and Computer Engineering, vol. 10, no. 1, pp. 1-14, 2020.

[6] H. Vahedi, A. Dehghanzadeh and K. Al-Haddad, "Static VAr compensator using packed U-cell based multilevel converter," 2018 IEEE 12th International Conference on Compatibility, Power Electronics and Power Engineering (CPE-POWERENG 2018), Doha, pp. 1-5, 2018.

[7] E. Can, H.H. Sayan, "A novel SSPWM controlling inverter running nonlinear device," Electrical Engineering, vol. 100, no. 1, pp. 39-46, 2018. 
[8] E. Can, H.H. Sayan, "The increasing harmonic effects of SSPWM multilevel inverter controlling load currents investigated on modulation index", Tehnički vjesnik, vol. 24, no. 2, pp. 397-404, 2017.

[9] J. S. Jagabar and V. Krishnaswamy, "An assessment of recent multilevel inverter topologies with reduced power electronics components for renewable applications," Renew. Sustain. Energy Rev., vol. 82, no. 3, pp. 3379-3399, 2018.

[10] F. Chabni, R. Taleb, and M. Helaimi, "Optimum SHEPWM for a new 21-level inverter topology using numerical optimization methods: experimental comparative study," JVC/Journal Vib. Control, vol. 24, no. 23, pp. 5556-5569, 2018.

[11] M. Srndovic, A. Zhetessov, T. Alizadeh, Y. L. Familiant, G. Grandi and A. Ruderman, "Simultaneous Selective Harmonic Elimination and THD Minimization for a Single-Phase Multilevel Inverter With Staircase Modulation," in IEEE Transactions on Industry Applications, vol. 54, no. 2, pp. 1532-1541, March-April 2018, doi: 10.1109/TIA.2017.2775178.

[12] M. Al-Hitmi, S. Ahmad, A. Iqbal, S. Padmanaban, and I. Ashraf, "Selective harmonic elimination in awide modulation range using modified Newton-raphson and pattern generation methods for a multilevel inverter" Energies, vol. 11, no. 2, pp. 1-16, 2018.

[13] S. Ahmad, I. Ashraf, A. Iqbal and M. A. A. Fatimi, "SHE PWM for multilevel inverter using modified NR and pattern generation for wide range of solutions," 2018 IEEE 12th International Conference on Compatibility, Power Electronics and Power Engineering (CPE-POWERENG 2018), Doha, 2018, pp. 1-6, doi: 10.1109/CPE.2018.8372498.

[14] E. Can, "Fault Determination and Analysis of Complex Switching Structure at Multilevel Inverter," Tehnički vjesnik, vol. 26, no. 2, pp. 398-404, 2019.

[15] K.Saleh, N.Hantouli, "A photovoltaic integrated unified power quality conditioner with a 27-level inverter",Telecommunication, Computing, Electronics and Control, vol. 17, no. 6, pp. 3232-3248, December 2019.

[16] Y. Zhou, F. He, and Y. Qiu, "Optimization of parallel iterated local search algorithms on graphics processing unit " J. Supercomput., vol. 72, no. 6, pp. 2394-2416, 2016.

[17] J. Ramesh Rahul, K.Annamalai, "Multistring seven-level quasi Z-source based asymmetrical inverter", Indonesian Journal of Electrical Engineering and Computer Science, vol. 15, no. 1, pp. 88-94, July 2019.

[18] E. Can, "Novel high multilevel inverters investigated on simulation," Electrical Engineering, vol. 99, no. 2, pp. 633-638, 2017.

[19] M. V. Rajkumar and T. Nadu, "Modeling and Simulation of Asymmetric Cascaded Multilevel Inverter with Reduced Switches using Multicarrier PWM Control," International Journal of Advanced Research in Electrical, Electronics and Instrumentation Engineering, vol. 5, no. 10, pp. 8064-8071, October 2016.

[20] M. S. A. Dahidah, G. Konstantinou, and V. G. Agelidis, "A Review of Multilevel Selective Harmonic Elimination PWM: Formulations, Solving Algorithms, Implementation and Applications, " IEEE Trans. Power Electron., vol. 30, no. 8, pp. 4091-4106, 2015.

[21] N. Vinoth et al., "Simulated Annealing Based Selective Harmonic Elimination for Multi-level Inverter " Energy Procedia, vol. 117, pp. 855-861, 2017.

[22] M. Rasheed, R. Omar, M. Sulaiman, W.Abd Halim, "A modified cascaded h-bridge multilevel inverter based on particle swarm optimisation (PSO) technique", Indonesian Journal of Electrical Engineering and Computer Science, vol. 16, no. 1, pp. 41-51, 2019.

[23] E. H. Aboadla, S. Khan, al, " A novel optimization harmonic elimination technique for cascaded multilevel inverter", Bulletin of Electrical Engineering and Informatics, vol. 8, no. 2, pp. 405-413, 2019.

[24] E. Deniz, O. Aydogmus, and Z. Aydogmus, "Implementation of ANN-based Selective Harmonic Elimination PWM using Hybrid Genetic Algorithm-based optimization," Meas. J. Int. Meas. Confed., vol. 85, pp. 32-42, 2016.

[25] M. Rasheed, R. Omar, M. Sulaiman, W.Abd Halim, "A modified cascaded h-bridge multilevel inverter based on particle swarm optimisation (PSO) technique", Indonesian Journal of Electrical Engineering and Computer Science, vol. 16, no. 1, pp. 41-51, 2019. 